Finisterra, XXXVI, 72, 2001, pp. 67-74

\title{
PAISAGEM - EM BUSCA DO LUGAR PERDIDO
}

Teresa Alves 1

\section{PAISAGEM/ARTE}

A noção de paisagem no Ocidente surgiu associada ao desenvolvimento da arte da pintura «Il est vrai que le paysage occidental, en tant que schéma de vision, est originairement pictural, (...) et qu'il est resté durablement, même en littérature, essentiellement tabulaire; (...) Ce n'est pas la peinture qui a induit le paysage, mas cette peinture-là qui, inventant un nouvel espace au Quattrocento, y a inscrit, progressivement et laborieusement, ce paysage-là.» (RoGER, 1997: 65).

A origem da palavra paisagem é atribuída ao poeta flamão Jean Molinet que, em 1493, a utilizou com o sentido de "quadro representando uma região» (Roger, 1997). Em 1549, no dicionário de francês-latim de Robert Estienne, o termo paisagem designava uma pintura sobre tela (PITTE, 1983). Com Ticiano, em 1552, paisagem passou a significar a representação pictórica de uma vista, normalmente como fundo de um quadro (BUESCU, 1990). Em 1690 o dicionário de Furetière descreveu a paisagem como o aspecto de uma região, o território que se estende até onde a vista pode alcançar, definição muito próxima da utilizada hoje no Petit Larousse (1994) «l'étendue de pays qui présente une vue d'ensemble» (MÉo, 1998). O termo paisagem, durante quase dois séculos, não foi utilizado para designar um facto geográfico, mas o produto da arte de representar numa tela um dado acontecimento enquadrado por uma dada realidade geográfica.

De acordo com a interpretação de Alexander Humboldt, a paisagem foi uma criação do homem urbanizado do norte da Europa (BuEscu, 1990). Para tal facto deverá ter sido decisiva a questão religiosa. Os pintores italianos desenvolveram, no século XIII, uma corrente de pintura em que estava implícita a utilização de elementos do naturalismo, mas como não conseguiram despojar a pintura dos aspectos religiosos não se impuseram no domínio da pintura da paisagem. Em contrapartida, escolas de pintura da paisagem foram-se afirmando na Flandres (século XV), na Holanda (século XVII), em Inglaterra

\footnotetext{
1 Professora Auxiliar da Faculdade de Letras da Universidade de Lisboa, Investigadora do Centro de Estudos Geográficos da Universidade de Lisboa. E-mail: ip226276@ip.pt
} 
(séculos XVIII e XIX) e em França (século XIX). As obras saídas destas escolas laicizaram a paisagem, libertando-a de qualquer referência religiosa; todavia, fizeram-no sob a influência da representação do espaço desenvolvida pelos pintores italianos (RogER, 1997).

A paisagem, no século XIX, esteve também presente em domínios da arte como as letras e a música. Na literatura a paisagem assumiu um lugar privilegiado nos trabalhos de autores como Flaubert e Balzac, em França, como as irmãs Brontë, em Inglaterra e Júlio Dinis, Almeida Garret e Camilo Castelo Branco, em Portugal (Buescu, 1990). Na música e após grandes obras numa linguagem universal como as de Bach, Haydn, Mozart ou Beethoven, surgiram, por exemplo, os trabalhos de Verdi (Itália), Chopin (Polónia), Tchaïkovski (Rússia), Falla (Espanha) ou Bartók (Hungria) que não só reflectiam a diversidade das paisagens musicais, como serviram de elementos aglutinadores na criação de identidades nacionais. Este movimento nas artes foi contemporâneo dos movimentos políticos de afirmação dos nacionalismos que se traduziram, frequentemente, em pretensões territoriais e que deram visibilidade a todo um conjunto de obras de arte em torno da paisagem - na pintura, na música e nas letras.

Real Life Landscape 2 é uma exposição de obras de arte que procura mostrar as mudanças na percepção e representação da paisagem. Assim, podemos ver desde os quadros de impressionistas (Matter and Spaces), como Claude Monet, até às representações de formas abstratas e coloridas (Marks and Locations; Structure and Shape), aos Inners Words dos surrealistas, como Magritte, Dali ou Miró. Esta exposição revela como a paisagem evoluiu da representação de um espaço geográfico, primeiro naturalista e depois abstrata, para a metáfora da representação dos mundos da mente, da imaginação, dos ideais. Se ao declínio do interesse pelas pinturas de Cézane ou Matisse corresponde a queda da importância económica e do estatuto social do campo e a ascensão da cidade, a partir de determinado momento a dinâmica da evolução é tal que a pintura, através das técnicas tradicionais, revela dificuldade em expressar as paisagens de um mundo em contínua mudança. A concepção de paisagem transforma-se - as paisagens são criadas pelas pessoas através da sua expe-riência e pelo seu envolvimento com o mundo que as rodeia - as formas de arte acompanham essa mudança. A velocidade da transformação assume uma di-mensão que torna necessário recorrer a outros tipos de arte, como a fotografia ou o filme ${ }^{3}$, que não só conseguem captar o tempo real das mudanças da paisagem, como podem ser transformadas em suportes intangíveis que, por sua vez, circulam em redes virtuais a velocidades antes impensáveis.

2 Real Life Landscape é uma exposição permanente da Modern Tate, em Londres.

3 O filme sonoro teve a «capacidade» de revelar uma das dimensões até então «ocultas» da paisagem: os sons. 
Na génese e concepção da noção de paisagem encontramos a representação na pintura, naturalista ou não, na música e nas letras de variadas realidades geográficas o que irá ter um papel decisivo na formação do olhar colectivo sobre o mundo ${ }^{4}$.

\section{VALORES PAISAGÍSTICOS: ESTÉTICA E PRODUÇÃO SOCIAL}

Esta génese deverá ser uma das justificações porque o discurso sobre a paisagem esteve até há bem pouco tempo imbuído de valores iminentemente associados a concepções estéticas: para ser paisagem, um território deveria ter uma apreciação estética favorável. É o processo que ALAIN Roger (1997) define como artialização: conquistar os territórios para a paisagem através de um processo de artialização, ou seja de transformar o espaço visível através de uma apreciação estética positiva.

A noção tradicional de paisagem esteve associada ao belo, mas até serem «transformados» em paisagem os espaços das montanhas ${ }^{5}$, das florestas ${ }^{6}$, dos desertos ${ }^{7}$ ou do mar ${ }^{8}$ eram espaços penosos e repulsivos. As razões da penosidade e da repulsa destes espaços estavam associadas, no caso das montanhas e dos desertos, ao rigor do clima, às dificuldades de circulação e ao medo do desconhecido, no caso do mar ao facto de ter havido, até determinado momento, uma certa fobia à água - a generalidade das pessoas não via o banho como algo de agradável - reforçada por razões religiosas: o pecado da exibição da nudez. À medida que os constragimentos religiosos desapareceram, a revolução técnica permitiu superar as dificuldades de circulação e aumentou o conhecimento sobre grandes extensões da superfície terrestre, e os valores sociais se alteraram - a higiene, a ecologia, os tempos livres e o lazer - estavam criadas as condições para que estes espaços de punição pudessem ser reavaliados, segundo novos modelos de valores, e apreendidos como paisagens.

Nalguns casos a criação dos valores paisagísticos associados a estes espaços resultaram de processos de imposição de um quadro, socialmente construído, que pouco tinha a ver com a realidade geográfica. Em relação aos desertos, por exemplo, a «reabilitação» surgiu com a descoberta dos depósitos de petróleo e

4 Segundo Roger (1997), o smog de Londres corresponde a uma invenção pictural, pois até surgir em determinados quadros não era digno de referência.

5 John Grand-Carteret (1983) - La montagne à travers les âges. Slatkine. Genève citado por ROGER (1997).

$6 \mathrm{O}$ actual apego aos passeios pelas florestas em Inglaterra levou a um movimento popular, em Abril de 2001, de contestação ao encerramento ao público de extensas áreas no Lake District devido à epidemia de febre aftosa. De acordo com RoGER (1997) num inquérito sobre as preferências turísticas dos franceses, as florestas surgiam classificadas à frente do litoral e das montanhas.

7 Chantal Gragon (1992) - Naissance du désert. Balland, Paris, citado por Roger (1997).

8 Alain Corbin (1988) - Le territoire du vide. Aubier, Paris, citado por Roger (1997). 
de gás natural e a paisagem «típica», que se difundiu, correspondia a grandes extensões de dunas com oásis de palmeiras. Esta imagem é ainda hoje tão forte que faz esquecer que mais de $80 \%$ dos desertos não têm estas características e são constituídos por calhaus e rochas (reg) ${ }^{9}$.

Na mesma lógica insere-se a criação da identidade territorial, a partir da paisagem dos parques nacionais nos EUA. Antes do turismo da segunda metade do século XX e da difusão massificada das imagens, foram os filmes sobre o Oeste que vulgarizaram estas paisagens junto do público de todo o mundo, difundindo a ideologia de fronteira, de apropriação igualitária do território, legitimando a colonização e a destruição das populações autóctones, construindo a identidade territorial americana (Méo, 1998). As paisagens consagradas nos filmes de western estão, todavia, longe de corresponderem às caracterís-ticas dos lugares onde realmente ocorreram os acontecimentos histó-

$\begin{array}{lllll}r & \mathrm{i} & \mathrm{c} & \mathrm{o} & \mathrm{s}\end{array}$ que correspondem ao argumento desses filmes. No entanto, com o passar do tempo, foram-se impondo à escala mundial e de tal forma que o cenário do western é assumido como o palco da história (Foucher, 1977). Hoje, mais do que nunca, os Parques Nacionais nos EUA constituem o modelo nacional de território, são as paisagens ideais: policiadas, vigiadas e respeitadas.

Modelos pictóricos, literários, cinematográficos, televisivos, publicitários, socialmente produzidos, modelam continuamente a experiência perceptiva de construção dos valores paisagísticos. Estes valores devem pois ser contextualizados em termos de tempo e de espaço, a maneira como as pessoas compreendem e se relacionam com o mundo que as rodeia depende do momento e do lugar.

\section{PAISAGEM: CRISE E MUDANÇA}

No principal instrumento de definição de estratégias de desenvolvimento para os próximos anos em Portugal - Plano Nacional de Desenvolvimento Económico e Social - a problemática da paisagem surge associada, de uma forma muito clara, às áreas rurais «(...) a particular atenção que será atribuída à requalificação urbana, ao apoio aos serviços sociais de proximidade, à valorização do povoamento e das paisagens rurais e, também, à defesa e preservação do ambiente, bem como à prossecução activa da sua integração transversal nas diversas políticas públicas, viabilizando a concretização de um processo de desenvolvimento sustentável. (...) O reforço e a consolidação do sistema urbano articulam-se necessariamente com a prioridade essencial atribuída ao desen-

9 Luís Sepúlveda, escritor chileno, numa das suas crónicas revela o facto de interrogados sobre o deserto de Atacama ser frequente as pessoas de terras distantes no Chile referirem como características as dunas e os oásis de palmeiras que nunca existiram neste deserto. 
volvimento rural, designadamente como elemento indispensável para o equilíbrio económico e social, como garantia do povoamento e da conservação e melhoria dos recursos naturais e das paisagens e, ainda, para assegurar o equilíbrio entre os valores tradicionais e os predominantemente urbanos, necessário à afirmação da nossa identidade nacional.» (MePAT, 1998:11).

Esta perspectiva da paisagem associada ao mundo rural tem subjacente duas questões: por um lado, a visão do mundo rural como apêndice da cidade e, que, como tal, deve ser domesticado, colonizado com uma evolução dependente das lógicas, necessidades e interesses urbanos; e, por outro, as noções de preservação e conservação por contraposição à valorização e à melhoria.

Proteger, salvaguardar, conservar que paisagens? Seleccionadas segundo que valores paisagísticos? Os valores paisagísticos são valores sócio-culturais construídos em determinados contextos de tempo e de espaço e, como tal, estão em contínua mudança e evolução. As paisagens identificadas como as que devem ser preservadas, algumas das quais consideradas como naturais, correspondem a modelos culturais herdados do passado, frequentemente, obsoletos. Esta visão da paisagem levanta sérios problemas em termos conceptuais, o que em países como a França deu origem a uma corrente de pensamento onde se questionava a morte da paisagem (ConAN, 1982). Sem dúvida que estamos a assistir à morte, não da paisagem, mas de uma determinada forma de conceber a paisagem, a paisagem dita tradicional, bucólica e idílica à semelhança das paisagens naturalistas dos românticos.

O processo de produção do espaço sofreu, nos últimos anos, uma transformação muito rápida que se traduz em alterações substanciais na organização do território. Constatamos a deterioração, mesmo a destruição, das paisagens bucólicas que através de agressões múltiplas podem ficar reduzidas a pedaços de terra, sem valor estético, económico ou cultural. Ao mesmo tempo, a manutenção dos espaços rurais é cada vez menos assegurada pelas populações autóctones, logo as lógicas de produção das paisagens destas áreas estão cada vez mais condicionadas a interesses estranhos às regiões, o que conduz à produção de paisagens diferentes das do passado. Por outro lado, nas periferias das cidades, transformadas em dormitórios ou em áreas industriais, surgem conjuntos de edificações, produto da sobreposição de várias lógicas de especulação fundiária, gerando espaços caóticos e de valor estético duvidoso. Os centros das cidades sucumbem às pressões de todo o tipo sendo necessárias medidas de política para a captação de meios económicos que possibilitem a valorização de paisagens culturais únicas. Face a esta situação, a noção de paisagem tem de ser necessariamente modificada, reassumindo outros valores sociais e culturais; caso contrário, estamos condenados a viver num mundo sem paisagem.

A crise actual da paisagem resulta, para Alain Roger (1997) de um duplo movimento de deterioração in situ e de abandono in visu. Mas este autor defende que esta situação é o resultado da esclerose do nosso olhar que continua em busca da estética bucólica associada a paisagens que já não existem. Parece-nos, todavia, que a superação desta crise obriga a algo mais do que reaprender 
a olhar. Da instância geográfica que nos cerca captamos impressões que podemos descodificar através da utilização não só dos sentidos - as imagens, os cheiros, os sabores, os sons, o tacto, como também dos sentimentos - o afecto, o prazer. O modo como operamos esta descodificação vai depender, por sua vez, de condicionamentos sociais e culturais que vão modelar a nossa experiência perceptiva, a nossa forma de construir a paisagem. A paisagem é não só o resultado de uma construção mental individual, como também o produto da evolução das representações colectivas.

Só através da concepção da paisagem como uma visão - sensorial, afectiva, simbólica, material - de um território vivido pelos indivíduos que o produzem, podemos desenvolver modelos capazes de interpretar e compreender a desordem das áreas industriais, o vanguardismo dos novos quarteirões das grandes metrópoles, o caos dos territórios do nosso quotidiano ou a velocidade das paisagens potenciadas pelos novos meios de comunicação ${ }^{10}$. Em termos teóricos, alguns trabalhos procuram demonstrar a beleza do caos ${ }^{11}$ ou procedem ao elogio da desordem ${ }^{12}$.

Torna-se, deste modo, necessário pensar na transformação da paisagem em termos de processos em evolução e não apenas em termos de conservação. Para tal, é fundamental compreender os mecanismos sociais e económicos que fazem evoluir a paisagem e, com base neste conhecimento, desenvolver um outro modo de planear e gerir o conjunto dos fenómenos que conduzem à produção da paisagem.

Ao contrário do passado, em que o mundo era visto à distância - dum ponto alto, de uma janela, num quadro, projectado num ecran, os sistemas mais avançados de informação geográfica e os sistemas interactivos de telecomunicações são os novos paradigmas de uma realidade onde não há palco e espectadores, qualquer que seja a paisagem - a realidade apercebida e deformada pelos sentidos e pelos sentimentos - a sua compreensão e evolução depende de todos nós, todos somos actores e fazemos parte integrante de um cenário em contínua transformação.

\section{PAISAGENS CRÍTICAS: EM BUSCA DO LUGAR PERDIDO}

O trabalho de geógrafos, como SoJA $(1989,2000)$, Harvey (1989), MaSSEY (1994) e GREGory (1994), colocaram em destaque as questões sociais e a construção de novas formas de organização do espaço. Nestes trabalhos as paisa-

10 Porque razão de avião todas as paisagens são bonitas? (1997).

11 Shionara Kasuo (1988) - La beauté du chaos. Cahiers du C.C.I., n. ${ }^{\circ}$ 5, citado por Roger

12 Alain Roger (1992) - Éloge du désordre. Chaos-Harmonie-Existence. École d'Architecture de Clermont-Ferrand, citado por Roger (1997). 
gens naturais surgiram como pano de fundo a desastres ecológicos ou a problemas ambientais como deslizamentos, as cheias, os lixos ou a poluição. As cidades marcaram presença através dos centros históricos degradados, das periferias caóticas ou através das diversas formas de exclusão, como os semabrigos, a solidão dos idosos, a criminalidade juvenil, o racismo, o processo de gentrification. Os complexos industriais abandonados transformaram-se em objectos de arqueologia e a desestrutuação social associada ao desemprego transformou-se no grande tema decorrente da reestruturação do trabalho. Os grandes centros do consumo revelaram a dinâmica económica, baseada na dependência das actividades financeiras, e o crescimento das disparidades no poder de compra que se traduziram no acelerar dos desequilíbrios sociais. O modelo de desenvolvimento dominante promoveu a construção de um mundo cada vez mais agressivo e com o qual dificilmente nos conseguimos identificar.

Atravessamos um momento em que a mundialização da economia, das comunicações e das trocas trazem o risco da uniformização das sociedades, do alinhar sob um mesmo modelo as representações, as mentalidades, as maneiras de consumir e, mesmo, o modo de organizar o espaço geográfico e de modelar as paisagens. Na Europa, na América do Norte e na Ásia os novos espaços das cidades são todos muito semelhantes, com edifícios de escritórios esteriotipados, construídos em vidro e aço, com grandes superfícies comerciais estruturadas da mesma forma e onde pontuam as lojas das mesmas marcas, com grandes condomínios de habitações de luxo, onde o preço pago é a garantia da uniformidade da paisagem social dos moradores. Nas áreas habitadas pelas populações mais desfavorecidas, a paisagem também tende a uniformizar-se através da proliferação das habitações degradadas, pela desestruturação das relações de pertença a um dado espaço, pelo desaparecimento das referências culturais das comunidades e pelo impor de modelos sociais em que impera o individualismo que destr espaços públicos de vivência colectiva. A tendência para a uniformização do território seguindo os chamados padrões ocidentais ajuda a destruir todas as outras formas de representação, produzindo espaços que nem sempre estão adaptados às condições de vida dos seus habitantes (HaRveY, 1989; SoJa, 1989) e onde é difícil construir relações de identidade. Fenómenos de identidade/desenraizamento, de integração/segregação, de inclusão/exclusão, de igualdade/desigualdade, da justa/injusta repartição das riquezas e dos meios de produzir traduzem-se em diferentes formas de organização dos territórios, mas que o processo de globalização em cursos tende a transformar em paisagens cada vez mais indiferenciadas.

Mais uma vez é através de uma forma de arte, a fotografia, que se estão a operar as principais mudanças no modo de captar o sentido destas realidades. Alguns fotógrafos contemporâneos revelam preferências por paisagens que em nada se assemelham com as representadas pelos pintores naturalistas. São as chamadas paisagens críticas (Roger, 1997). Obras, como as de Sebastião Salgado - Trabalho e Exodus - revelam a profunda desigualdade e as condições inumanas das paisagens que retratam, sem nunca perder, todavia, a dimensão 
da dignidade humana. No mesmo movimento insere-se o trabalho Paysages photographies. En France les années quatre-vingt da missão fotográfica da DATAR (1989). O choque é frequente, mas a força da denúncia e da crítica subjacentes as estas imagens pode ajudar a construir novos modelos de valores que nos permitam viver no meio destas paisagens que nos suscitam repulsa. Tal facto não significa aceitar a injustiça das situações, mas desenvolver mecanismos para as compreender e, em seguida, actuar para as transformar.

$\mathrm{Na}$ medida em que a paisagem exprime as facetas sensoriais dos territórios, em domínios tão variados como a afectividade, o imaginário e a aprendizagem sócio-cultural, a paisagem tem de ser construída como um sistema identitário e nunca poderá ser reductível à materialidade do mundo físico. A paisagem deve ser assumida como um dos elementos centrais do sistema cultural, uma espécie de montagem ordenada de objectos (materiais e imateriais) que actua como um sistema de significados através do qual o sistema social é comunicado, reproduzido, experimentado e explorado (DunCan, 1988).

\section{BIBLIOGRAFIA}

BuEscu, H. (1990) - Incidências do olhar: percepção e representação. Caminho. Lisboa

Conan, M. (ed.) (1982) - Mort du paysage? Seyssel, Champ Vallon.

Datar (1989) - Paysages photographies. En France les années quatre-vingt. Hazen, Paris.

Méo, G. Di (1998) - Géographie sociale et territoires. Éd. Nathan, Paris.

Duncan, M. (1988) - (Re)reading the landscape. Environment and Planning D: Society and Space 6: 117-126.

Foucher, M. (1977) - Du désert, paysage du Western. Hérodote, 7: 106-116.

Gregory, D. (1994) - Geographical imaginations. Blackwell, Cambridge e Oxford.

HARVEY, D. (1989) - The conditions of postmodernity. Blackwell, Oxford.

MASsEY, D. (1994) - Space, place and gender. Blackwell, Oxford.

Mepat (1998) - Plano Nacional de Desenvolvimento Económico e Social. Secretaria de Estado do Planeamento e do Desenvolvimento Regional, Lisboa. In PITTE, J. R. (1983) - Histoire du paysage français. Tallandier. Paris.

Roger, A. (1997) - Court traité du paysage. Ed. Gallimard, Paris.

Salgado, S. (1996) - Trabalho.Caminho, Lisboa.

Salgado, S. (1998) - Exodus.Caminho, Lisboa.

SEN, A. (2000) - Repenser l'inégalité. Seuil, Paris.

SoJA, E. (1989)-Postmodern geographies: the reassertion of space in critical social theory. Verso, Londres.

SoJA, E. (2000) - Postmetropolis. Blackwell, Cambridge MA e Oxford UK. 